\title{
Pan-Canadian REspiratory STandards INitiative for Electronic Health Records (PRESTINE): 2011 National Forum Proceedings
}

\author{
M Diane Lougheed MD MSc FRCPC ${ }^{1,2 *}$, Janice Minard RN MSc ${ }^{1,2}$, Shari Dworkin ${ }^{3}$, \\ Mary-Ann Juurlink BScH ${ }^{4}$, Walley J Temple MD $^{5}$, Teresa To BSc MSc PhD ${ }^{6}$, Marc Koehn BSc MBA7, \\ Anne Van Dam ${ }^{8}$, Louis-Philippe Boulet MD FRCPC ${ }^{9 *}$
}

\begin{abstract}
MD Lougheed, J Minard, S Dworkin, et al. Pan-Canadian REspiratory STandards INitiative for Electronic Health Records (PRESTINE): 2011 National Forum Proceedings. Can Respir J 2012;19(2):117-126.
\end{abstract}

In a novel knowledge translation initiative, the Government of Ontario's Asthma Plan of Action funded the development of an Asthma Care Map to enable adherence with the Canadian Asthma Consensus Guidelines developed under the auspices of the Canadian Thoracic Society (CTS). Following its successful evaluation within the Primary Care Asthma Pilot Project, respiratory clinicians from the Asthma Research Unit, Queen's University (Kingston, Ontario) are leading an initiative to incorporate standardized Asthma Care Map data elements into electronic health records in primary care in Ontario. Acknowledging that the issue of data standards affects all respiratory conditions, and all provinces and territories, the Government of Ontario approached the CTS Respiratory Guidelines Committee. At its meeting in September 2010, the CTS Respiratory Guidelines Committee agreed that developing and standardizing respiratory data elements for electronic health records are strategically important. In follow-up to that commitment, representatives from the CTS, the Lung Association, the Government of Ontario, the National Lung Health Framework and Canada Health Infoway came together to form a planning committee. The planning committee proposed a phased approach to inform stakeholders about the issue, and engage them in the development, implementation and evaluation of a standardized dataset. An environmental scan was completed in July 2011, which identified data definitions and standards currently available for clinical variables that are likely to be included in electronic medical records in primary care for diagnosis, management and patient education related to asthma and COPD. The scan, sponsored by the Government of Ontario, includes compliance with clinical nomenclatures such as SNOMED-CT ${ }^{\circledR}$ and LOINC ${ }^{\circledR}$. To help launch and create momentum for this initiative, a national forum was convened on October 2 and 3, 2011, in Toronto, Ontario. The forum was designed to bring together key stakeholders across the spectrum of respiratory care, including clinicians, researchers, health informaticists and administrators to explore and recommend a potential scope, approach and governance structure for this important project. The Pan-Canadian REspiratory STandards INitiative for Electronic Health Records (PRESTINE) goal is to recommend respiratory data elements and standards for use in electronic medical records across Canada that meet the needs of providers, administrators, researchers and policy makers to facilitate evidence-based clinical care, monitoring, surveillance, benchmarking and policy development. The focus initially is expected to include asthma, chronic obstructive pulmonary disease and pulmonary function standards elements that are applicable to many respiratory conditions. The present article summarizes the process and findings of the forum deliberations.

Key Words: Asthma; Clinical practice guidelines; Clinical variables; COPD; Data definitions; Electronic health records; Electronic medical records; Knowledge translation; Respiratory data sets; Surveillance

\section{L'Initiative PRESTINE sur les normes respiratoires pancanadiennes pour les dossiers de santé électroniques : les délibérations du forum national 2011}

\begin{abstract}
Dans une nouvelle initiative de transfert du savoir, le Plan d'action contre l'asthme du gouvernement de l'Ontario a financé l'élaboration d'un plan de soins standard pour l'asthme afin de favoriser le respect des Lignes directrices consensuelles canadiennes sur l'asthme élaborées sous les auspices de la Société canadienne de thoracologie (SCT). Après son évaluation positive dans le cadre du projet pilote sur les soins primaires de l'asthme, des cliniciens en santé respiratoire de l'unité de recherche sur l'asthme de l'université Queen's, à Kingston, en Ontario, dirigent une initiative pour intégrer les éléments des données du plan de soins standard pour l'asthme aux dossiers de santé électroniques en soins primaires de la province. Conscient que les normes des données touchent tous les troubles respiratoires ainsi que l'ensemble des provinces et des territoires, le gouvernement de l'Ontario a pris contact avec le comité des lignes directrices canadiennes en santé respiratoire de la SCT. Lors de sa réunion de septembre 2010, ce comité a convenu de l'importance stratégique d'élaborer et de normaliser les éléments des données respiratoires en prévision des dossiers de santé électroniques. Pour faire suite à cet engagement, des représentants de la SCT, de l'Association pulmonaire, du gouvernement de l'Ontario, du Cadre de travail national sur la santé pulmonaire et de l'Inforoute Santé du Canada se sont réunis pour former un comité de planification. Ce comité a proposé une démarche progressive pour informer les intervenants de la question et les faire participer à l'élaboration, à la mise en œuvre et à l'évaluation d'un ensemble de données standardisées. Une analyse du contexte, terminée en juillet 2011, a permis d'établir les définitions des données et les normes courantes relatives aux variables cliniques susceptibles d'être incluses dans les dossiers de santé électroniques en soins primaires dans le cadre du diagnostic, de la prise en charge et de l'éducation des patients à l'égard de l'asthme et de la maladie pulmonaire obstructive chronique. Cette analyse, subventionnée par le gouvernement de l'Ontario, inclut le respect de nomenclatures cliniques comme SNOMED-CT ${ }^{\circledR}$ et LOINC $^{\circledR}$. Pour contribuer à lancer et à renforcer cette initiative, un forum national a eu lieu les 2 et 3 octobre 2011 à Toronto, en Ontario. Ce forum visait à rassembler les principaux intervenants du spectre des soins respiratoires, y compris les cliniciens, les chercheurs, les informaticiens en santé et les administrateurs, afin d'explorer et de recommander une portée, une démarche et une structure de gouvernance potentielles pour ce projet d'importance. L'objectif de l'Initiative PRESTINE sur les normes respiratoires pancanadiennes pour les dossiers de santé électroniques consiste à recommander les éléments et normes des données respiratoires à utiliser dans les dossiers de santé électroniques au Canada, lesquels respectent les besoins des dispensateurs, des administrateurs, des chercheurs et des décideurs, afin de faciliter les soins cliniques, le contrôle, la surveillance, l'analyse comparative et l'élaboration de politiques fondés sur des données probantes. On envisage d'abord de se concentrer sur l'asthme, la maladie pulmonaire obstructive chronique et les éléments des normes de la fonction pulmonaire qui sont applicables à de nombreux troubles pulmonaires. Le présent article résume le processus et les observations tirées des délibérations du forum.
\end{abstract}

*Chairs. ${ }^{*}$ Division of Respirology, Department of Medicine, Kingston General Hospital at Queen's University; ${ }^{2}$ Asthma Research Unit, Kingston

General Hospital, Kingston, Ontario; ${ }^{3}$ Standards Collaborative, Canada Health Infoway; ${ }^{4}$ Ontario Lung Association, Toronto, Ontario;

${ }^{5}$ University of Calgary, AHS Cancer Surgery Alberta, Calgary, Alberta; ${ }^{6}$ Child Health Evaluative Sciences, The Hospital for Sick Children,

Toronto, Ontario; ${ }^{7}$ Gordon Point Informatics Ltd, Victoria, British Columbia; ${ }^{8}$ Canadian Lung Association, Ottawa, Ontario; ${ }^{9}$ Centre de

Pneumologie, Institut universitaire de cardiologie et de pneumologie de Québec, Québec, Québec

Correspondence and reprints: Canadian Thoracic Society, 300-1750 Courtwood Crescent, Ottawa, Ontario K2C 2B5.

Telephone 613-569-6411,fax 613-569-8860, e-mail info@lung.ca 


\section{INTRODUCTION}

\section{Louis-Philippe Boulet, M Diane Lougheed}

At least $20 \%$ of the Canadian population suffers from one or more respiratory diseases (1). Asthma and chronic obstructive pulmonary disease (COPD) are two of the most common chronic respiratory diseases. Despite improved understanding and better treatment strategies for these conditions, they are still responsible for a large human and socioeconomic burden $(2,3)$. In this regard, the estimated aggregate cost of respiratory diseases to the Canadian health care system in 2000 was estimated by the Public Health Agency of Canada to be $\$ 5.6$ billion (www.phac-aspc.gc.ca).

Rapid scientific advances and an exponentially increasing volume of literature make it difficult for health professionals to keep abreast of optimal care. To address this problem, clinical practice guidelines (CPGs) have been developed to make evidence-based recommendations regarding the diagnosis and management of various health conditions (4). The Canadian Thoracic Society (CTS) aims to reduce the burden of respiratory disease among Canadians by promoting the best respiratory care. To help achieve this goal, the CTS has produced and disseminated numerous respiratory guidelines since the 1980s (5).

In the past few years, the CTS created the Canadian Respiratory Guidelines Committee (CRGC) to standardize the guideline development process and ensure adherence with optimal methodologies for producing and disseminating these documents. The structure of the CRGC and the guideline development process have been previously published (6). An important mandate of the CRGC is to promote the implementation of CTS guidelines, and various strategies have been proposed in keeping with the best evidence in the knowledge translation field $(7,8)$.

The electronic health record (EHR) may be viewed as an emerging knowledge translation tool, which offers an opportunity to promote the implementation of key recommendations from guidelines into current care. The EHR offers not only a means of integrating guidelines into day-to-day clinical practice, but also to evaluate the effects of interventions and treatments on the population. A list of benefits of EHRs is presented in Table 1.

The CTS and CRGC recognize the need to promote the standardization of data elements in the EHR, particularly to ensure interoperability. Standardized data collection can clearly benefit the full spectrum of stakeholders, but also places a clear demand on clinicians, researchers and guideline developers to establish guideline implementation initiatives to support uptake and reduce care gaps; enhance quality management, evaluation and surveillance through access to and use of electronic medical records (EMRs)/EHRs; and collaborate to ensure that systems are designed to collect valid, relevant respiratory information for performance measurement (eg, quality of life instruments).

The Pan-Canadian REspiratory STandards INitiative for Electronic Health Records (PRESTINE) is a project of the CTS, the medical section of the Canadian Lung Association working in collaboration with The Ontario Lung Association and the National Lung Health Framework. PRESTINE builds on work currently underway in Ontario to establish data standards for respiratory care and aims to extend this work on a pan-Canadian basis.

The main goal of the PRESTINE National Forum 2011 was to initiate discussions to develop a common language for guidelinesbased indicators of chronic disease management of asthma and COPD applicable to EMRs used in primary care. Stakeholders were invited to provide input regarding the PRESTINE project scope, governance and operational structure including sponsor organizations, steering committee, working group(s) and project team. Six grounding didactic presentations provided participants with the following: an overview of the status of EHRs in Canada; an example of a 'success story' using synoptic reporting for cancer surgical outcomes in Alberta; Ontario's experience developing and implementing asthma electronic records; the development and feasibility of implementing asthma care performance indicators in primary care in Ontario; the status of data standards

\section{TABLE 1}

\section{Potential benefits of electronic health records and standardized data elements}

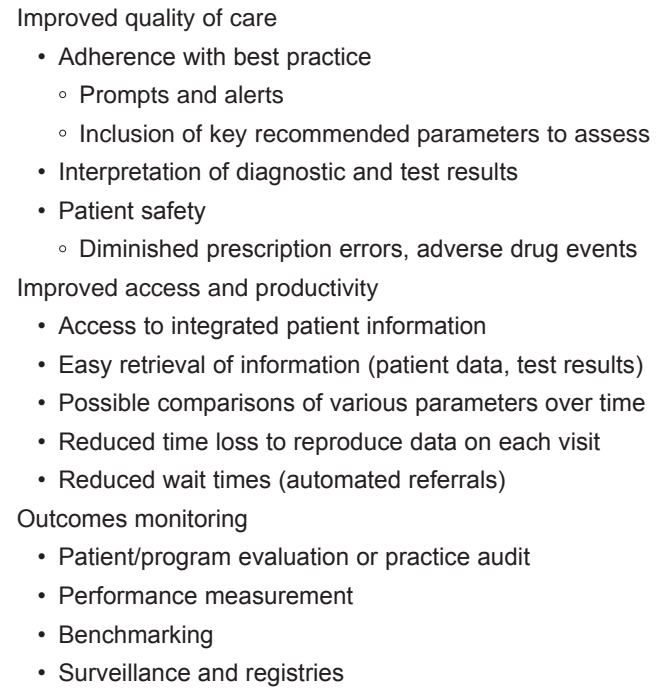

for asthma and COPD in primary care; and development of an asthma and COPD data standard.

On the second day, large and small group discussions were facilitated to establish a project goal statement, agree on project scope and guiding principles, and identify resources as well as potential partners and collaborating agencies. The present document summarizes the workshop proceedings and presents a strategy for a national PRESTINE initiative.

\section{REFERENCES}

1. Canadian Institute for Health Information, Canadian Lung Association, Health Canada, Statistics Canada. Respiratory Disease in Canada, 1st edn. Ottawa: Health Canada, 2001:1-102.

2. Fitzgerald JM, Boulet LP, McIvor RA, et al. Asthma control in Canada remains suboptimal. Can Respir J 2006;13:253-9.

3. O'Donnell DE, Aaron S, Bourbeau J, et al; Canadian Thoracic Society. Canadian Thoracic Society recommendations for management of chronic obstructive pulmonary disease -2003 . Can Respir J 2003;10(Suppl A):11-65.

4. Burgers J, Grol R, Eccles M. Clinical guidelines as a tool for implementing change in patient care. In: Grol R, Wensing M, Eccles $\mathrm{M}$, eds. Improving Patient Care: The Implementation of Change in Clinical Practice. Oxford: Elsevier, 2005:71-92.

5. Boulet LP, Becker A, Bowie D, et al. Implementing practice guidelines: A workshop on guidelines dissemination and implementation with a focus on asthma and COPD. Can Respir J 2006;13(Suppl A):5-47.

6. Gupta S, Bhattacharyya OK, Brouwers MC, et al. Canadian Thoracic Society: Presenting a new process for clinical guideline production. Can Respir J 2009;16:e62-e68.

7. Boulet LP. Improving knowledge transfer on chronic respiratory diseases: A Canadian perspective. How to translate recent advances in respiratory diseases into day-to-day care. J Nutr Health Aging 2008; $12: 758$ s-63s.

8. Boulet LP, FitzGerald MF, Levy ML, et al. Asthma guidelines implementation: A guide to the translation of the Global Initiative for Asthma Strategy into improved care. Eur Resp J 2012 (In press).

\section{SECTION I. THE STATUS OF EHRs IN CANADA Shari Dworkin}

Canada Health Infoway (Infoway) is an independent, not-for-profit corporation created by Canada's First Ministers in 2001. It is accountable to 14 federal, provincial and territorial governments. Infoway jointly invests with every province and territory to accelerate the development and adoption of information and communications technology projects for health. Fully respecting patient confidentiality, these secure systems will support safe care decisions and help patients manage their own health. 
Infoway's vision is for a highly sustainable and effective Canadian health care system supported by an infostructure that provides residents of Canada and their health care providers with timely, appropriate and secure access to the right information when and where they enter the health care system. Infoway has 12 targeted investment programs with a total funding allocation of $\$ 2.1$ billion. As of September 30,2011 , there were 340 active or completed projects.

The roles of Infoway are to:

- provide a technology framework to guide EHR development;

- support and sustain communications and technology standards that enable health information systems to share patient health information accurately and securely;

- invest jointly with provinces and territories to implement information and communications technology projects for health;

- provide tools and services to technology vendors to accelerate EHR development and implementation; and

- foster and support clinical adoption of EHRs (1).

Infoway's Standards Collaborative was established in 2006 to support and sustain health information standards and foster collaboration to accelerate the implementation of pan-Canadian standards-based solutions to realize this vision. The collaborative provides the processes, resources and governance structure for building pan-Canadian consensus-based health information standards.

What is a health information standard?

A pan-Canadian health information standard is defined as a document, established by pan-Canadian consensus, which provides for common and repeated use, rules, guidelines or characteristics for activities or their results, aimed at the achievement of the optimum degree of order in a given Canadian health informatics context (2). Standards documents are designed and intended for broad use in Canada and are approved through the Infoway Standards Collaborative Governance process.

Standards support integrated, patient-centric health records enabling a longitudinal view of an individual's key health history and care, including patient visits, hospitalizations, diagnostic images and reports, laboratory test results, prescribed drugs and immunizations. They also ensure that common terminologies are in place to describe, record and aggregate diagnoses, medications and other key clinical information, and that this critical information can be updated, managed, shared and interpreted in a meaningful and secure way, when and where required (2).

As a specification progresses through the standards 'life cycle', from development to maintenance, each stage is reviewed and approved at specific decision points defined in the decision-making process as follows:

- Canadian Strategy Selection

- Canadian Draft For Use

- Canadian Approved Standard

- Canadian Deprecated

What is the status of EHR standards in Canada?

To date, several pan-Canadian Standards have been established, including standards for client and provider registries, laboratory systems, diagnostic imaging, drugs, interoperability of EHRs, public health surveillance, national e-Claims, transport level interoperability and data security (2). Many of these standards include codified clinical terminology.

\section{Systematized NOmenclature of MEDicine Clinical Terms ${ }^{\circledR}$} considerations

Systematized NOmenclature of MEDicine Clinical Terms (SNOMED-CT ${ }^{\circledR}$ ) is a key terminology standard selected by Canadian stakeholders for use in information and communication technologies for health. It is already in use in more than 50 countries. SNOMED-CT ${ }^{\circledR}$ facilitates the interoperability of EHRs by enabling clinical data to be captured, retrieved, aggregated and shared across health care settings and providers in a reliable, safe way. SNOMED-CT ${ }^{\circledR}$ specifically features codes for more than 300,000 clinical concepts, ranging from diagnoses to medication orders. Each concept is linked to multiple descriptions, which allows clinicians to express a clinical concept in a way they would prefer without losing its intended meaning. The value of SNOMED-CT ${ }^{\circledR}$ can be illustrated through the example of heart attack. While there are many different ways to describe the condition (eg, myocardial infarction, cardiac infarct) they all share the same unique code and meaning.

SNOMED-CT ${ }^{\circledR}$ was developed by clinicians for clinicians. As with all coding standards, clinicians will use solutions when effective change management strategies and user interfaces are designed. Implementers are leveraging what they need from SNOMED-CT ${ }^{\circledR}$ to meet their business and clinical needs (eg, reference sets). There are more than 20 planned and/or SNOMED-CT ${ }^{\circledR}$-enabled implementation initiatives in Canada. Examples range from large-scale panCanadian implementations to small primary care clinics.

\section{Key points}

- Infoway is an independent, not-for-profit corporation created to foster and accelerate the development and adoption of information and communications technology systems for health (www.infowayinforoute.ca)

- Infoway's Standards Collaborative supports and sustains health information standards and fosters collaboration to accelerate the implementation of pan-Canadian standards-based solutions

- SNOMED-CT ${ }^{\circledR}$ is a key terminology standard selected by Canadian stakeholders for use in information and communication technologies for health.

\section{REFERENCES}

1. About Canada Health Infoway. What we do section. Canada Health Infoway. <www.infoway-inforoute.ca/an-en/standards-collaborative> (Accessed February 23, 2012).

2. Standards Collaborative Guide. Canada Health Infoway. ISO/IEC Guide 2:2004, Standardization and related activities - general vocabulary. <www.infoway-inforoute.ca/ang-en/standards-collaborative> (Accessed February 23, 2012).

\section{SECTION II. MEASURE TODAY, CHANGE TOMORROW} Walley J Temple

Extensive literature identifies that outcomes of cancer patients are significantly linked with the quality of surgery, particularly as it relates to the adherence to guidelines. Incorporation of guidelines in cancer surgery has resulted in increases in survival by up to $10 \%$ and decreases in morbidity, costs and resource utilization by $20 \%$ to $30 \%(1,2)$. Unfortunately, despite the scientific validity of guidelines, their incorporation into practice has been disappointing. Latosinsky et al (3) documented this phenomenon after Canadian breast cancer guidelines were introduced in 1998 in Manitoba. As measured by three quality measures in more than 7000 breast cancer patients, there was no effect on the change in practice three years after guideline publication.

This challenge provided the impetus for the Alberta Cancer Board to fund the development of Cancer Surgery Alberta in 1999, to improve the surgical care of cancer patients across the province. The strategy to seamlessly introduce guidelines into a surgeon's practice was to harness the EMR in an entirely new way. The traditional EMR is a view-only document. We embarked on a project to develop software that would exploit the EMR's dynamic capability to record a web-based operative report with a structured synoptic format available to all practitioners across the province. The data entered not only produces the operative report, but real-time outcomes can also be generated. This format allows for the introduction of explicit and implicit guidelines to be integrated into the surgeon's practice as they 
complete the record. The prospect of surgeons assessing their outcomes and being able to compare these with their colleagues in aggregate form was the main driver for the adoption of an electronically generated synoptic operative report. However, it had to be equally as efficient and not require an additional narrative document.

To shift from the narrative record, which has been the gold standard for medical records for more than 3000 years, we also had to demonstrate that the synoptic format results in an equivalent record. A number of studies, including our own, have documented the erratic quality of narrative records, which provide on average fewer than $50 \%$ of the details required for subsequent care (4). There was no difference in the quality of information whether it was completed by trainees, specialists or subspecialists.

In addition to a significant improvement in quality, the synoptic record has many other attributes. It has created a standard for surgical care supported by the Alberta surgeon community. The record can be reviewed in real time and submitted with an electronic signature to be distributed instantaneously to all care providers including the hospital, pathology, the Alberta Cancer Registry, the Cancer Centre, as well as all referring physicians. This concept was tested with an Infoway investment in 2006, which showed that synoptic reporting was successfully introduced in five regions, using six templates, over two years. The evaluation showed that the recording of a breast cancer operation took less than $5 \mathrm{~min}$, with $97 \%$ of records completed in one day. The templates were educational and provided instant links to current guidelines, which could be accessed while entering information into the record. The elimination of transcription saved at least $\$ 100$ per record. Even more importantly, it saved health care personnel significant time by removing the need for reading a typical 1000 - to 2000-word report, instead reducing it to 10 to 20 key phrases that enabled them to determine subsequent management. In Alberta, if this format were used for all cancer operations, it would eliminate more than $15,000,000$ words of transcription per year. Alberta surgeons have made a unique contribution by demonstrating that a dynamic medical procedure, such as an operative procedure, can be represented by a synoptic record.

To date, more than 18,000 reports have been voluntarily submitted, completely encompassing six tumour sites: gynecology oncology, sarcoma, cutaneous, breast, endocrine and gastroenterological. In addition, a number of templates are being tested, including lung cancer, prostate cancer, hospital discharge summary, nurse navigation and some general surgical operations. This methodology has also been adopted by radiation oncology for cervical cancer and prostate cancer, and test templates have been created by medical oncology in neurosciences. This concept has also been tested in other areas of medicine using the Alberta webSMR technology, demonstrating its applicability to all types of medicine.

During the process of developing these templates, surgeons wanted to expand them to include all pertinent preoperative care pathways. This included such elements as clinical staging, functional issues, decision making, tumour banking records, tumour biology (ie, response to preoperative treatment) and follow-up triage. These are all data elements that a surgeon inherently knows, or should know, when they perform a cancer operation. This has significantly expanded the functionality of an operative report and is the beginning of synoptic incorporation of care pathways in our practices.

The change management principles that were necessary included the use of text-entered commentary, avoiding elements that might direct inappropriate practice, capturing all current or reasonable practice options, eliminating unimportant details (such as type of staples for bowel anastomosis, the incidentals of ligating vessels or suture types) so that only meaningful data are captured, and allowing for a dictated addendum $(1,2,5,6)$.

Recently, the option of dictating an addendum was assessed in 3366 consecutive reports; only five addendums and 21 redictations were found, the latter missing at least two key surgical processes despite having the template to remind them of the required items. Once again, this emphasizes the variability of the narrative report.
We have generated critical outcome information, examples of which are provided. In more than 6000 breast cancer reports, we have identified that only $50 \%$ are found radiologically and all but $4 \%$ of the remainder are found by the patient. This is a measure of our breast screening system in our province, which, if fully utilized, could identify $80 \%$ of all breast cancers. What is extremely valuable is that any intervention to increase the adoption of breast screening will be reflected within two to three months in the surgeon's outcomes. Our information also documents that Alberta surgeons adopted guidelines for using sentinel lymph node detection in breast cancer staging before the Canadian guidelines identified this practice as a standard, as a direct result of the template usage and a provincial workshop on sentinel lymph node surgery. It also identified how surgeons interpret guidelines regarding breast conservation, the current overall rate being $48 \%$. However, the information generated for the decision-making question identified that only $65 \%$ were candidates for breast conservation, so that the true rate is $78 \%$, an exceptional result. It also generated systems measures such as body mass index differences in patients among five regions, differences in regional stage IV presentation in breast cancer and a wide range of wait times. Noncancer issues, such as the use of prophylactic antibiotics and deep vein thrombosis prophylaxis, showed wide variation in practice with an enormous potential for cost savings if standard care was implemented.

The literature conclusively demonstrates that outcomes feedback is the most powerful educational tool to change practice (1). We have monitored surgical care of rectal cancer from 1996 to 2009, with implementation of feedback introduced in 2006. During this period, the use of abdominal perineal resections decreased from $43 \%$ to $29 \%$, and the use of the standard for resection (total mesenteric excision) increased from $20 \%$ to $98 \%$.

This work formed the impetus for Canadian Partners Against Cancer (CPAC) to implement a pan-Canadian initiative to adopt synoptic operative reporting. The Surgical Reporting Tools Project (SRTP) was funded from 2008 to 2012, and has successfully concluded with adoption in pilot sites in Nova Scotia, Quebec, Ontario and Manitoba in addition to Alberta. Four templates were used (ovarian, colorectal, breast and oral cancer). Both rural and urban sites participated and more than 5000 reports were completed.

Just as there were differences in Alberta among regions, the SRTP evaluation identified potentially significant differences across the provinces. These observations provide enormous potential for measuring real-time issues of care and identifying strategies to improve outcomes in Canada. This is a major success story for CPAC.

In summary, a digitized synoptic operative reporting system, which captures the surgeon's knowledge of the pre- and intraoperative care pathway, creates a critical bank of information that is key to understanding the dynamics of patient care and the biology of disease in our own practices, provinces and country. This format elevates a surgeon's involvement in patient care from that of an art to a science - a new standard of clinical documentation. The Alberta Canada Health Investment and the CPAC SRTP project have conclusively demonstrated that this methodology is transportable across regions, provinces, specialties and languages. It is time to consider synoptic reporting in cancer surgery as a standard information management tool to improve the outcomes of cancer patients and to expand it to other areas of medicine.

\section{REFERENCES}

1. Mack LA, Dabbs K, Temple WJ. Synoptic operative record for point of care outcomes: A leap forward in knowledge translation. Eur J Surg Oncol 2010;36(Suppl 1):S44-9. Epub 2010 Jul 6

2. Mack LA, Bathe OF, Herbert MA, et al. Opening the black box of cancer surgery quality: WebSMR and the Alberta experience. J Surg Oncol 2009;99:525-30.

3. Latosinsky S, Fradette K, Lix L, Hildebrand K, Turner D. Canadian breast cancer guidelines: Have they made a difference? CMAJ 2007;176:771-6. 
4. Edhemovic I, Temple WJ, de Gara CJ, Stuart GC. The computer synoptic operative report - a leap forward in the science of surgery. Ann Surg Oncol 2004;10:941-7.

5. Temple WJ, Francis WP, Tamano E, Dabbs K, Mack LA, Fields A, Cancer Surgery Alberta. Synoptic surgical reporting for breast cancer surgery: an innovation in knowledge translation. Am J Surg 2010;199:770-5. (Epub 2010 Feb 16)

6. Chambers AJ, Pasieka JL, Temple WJ. Improvement in the accuracy of reporting key prognostic and anatomic findings during thyroidectomy by using a novel Web-based synoptic operative reporting system. Surgery 2009;6:1090-8.

\section{SECTION III. THE ONTARIO EXPERIENCE: ELECTRONIC ASTHMA CARE MAP IN PRIMARY CARE PILOT}

M Diane Lougheed, Janice Minard

In 2000, following recommendations from an inquest into the death of a young man from asthma, the Government of Ontario established the 'Asthma Plan of Action', a collaborative integrated strategy consisting of 13 initiatives with a focus on health promotion, prevention, surveillance, evaluation and asthma management (1). One of these Asthma Plan of Action-funded initiatives was the Primary Care Asthma Pilot Project (PCAPP, 2002 to 2006), which enrolled patients from eight primary care locations to evaluate an asthma care program. The program, delivered by certified asthma educators, was comprised of the Ontario Lung Association's (OLA's) Asthma Care Map (ACM) for Primary Care and OLA's asthma action plan, a management algorithm and generic program standards (2). At 12 months follow-up, there were significant reductions in self-reported exacerbations, emergency room visits due to asthma, school absenteeism in children, and both daytime and nighttime symptoms (2). In 2006, the Government of Ontario funded the transition of this pilot project to the Primary Care Asthma Program (PCAP). PCAP is currently coordinated by the OLA, guided by an Advisory Committee, and is available in 12 primary care sites involving over 100 locations.

In PCAPP, although most of the sites had access to an EMR, providers were using a paper copy of the ACM and action plan. Recognizing that EMRs are becoming the standard of practice for documentation and communication in health care, a review of the literature was undertaken to ascertain the status of an electronic asthma data set in use in primary care (3). Only 76 of the 309 articles identified met the inclusion criteria for the review, and were categorized by the type of EMR and theme addressed. Most primary care articles reported on the status or utility of EMRs. Of the 76 asthma articles, only 17 were related to asthma primary care EMRs; most of these reported on decision support tools $(n=3)$ and/or utility $(n=14)$, specifically the ability to predict mortality, assess severity and timeliness of diagnosis. A standardized asthma data set was not found in this literature review.

As a next step in the asthma strategy, two primary care sites in Ontario participated in a five-month observational study. In this pilot, we demonstrated that it was feasible to incorporate the majority of data elements in the ACM into an electronic format (4). Asthma educators, at both sites, documented on the care map in the electronic record, which automatically produced individual patient summaries for the patient chart. De-identified data were sent in real time (daily or weekly) to a central secure server for analysis and generation of summary reports (by individual, site and aggregate reports) without any loss of data or security breaches. There were many challenges encountered during the pilot, which are outlined in Table 2.

The primary lessons learned from the e-record pilot project were that EMR data are reliable only if there are standardized data definitions; and that data standards are needed to enable 'interoperability' (ie, the ability for EMRs to communicate with one another). Data definitions were developed for the majority of the care map data elements. Elements in the care map were cross referenced with the SNOMED-CT ${ }^{\circledR}$ and Logical Observation Identifier Names and Codes $\left(\right.$ LOINC $\left.^{\circledR}\right)$, two
TABLE 2

\section{Challenges in the Asthma Care Program e-Record Pilot} Project

Process Issues

Collaborating with various health care models, each with their own approval processes

Different composition of interdisciplinary teams at various sites

Understanding and applying privacy and security legislation

Need for site-specific ethics approval or lack of process for ethics approval at sites

Differing opinions regarding the need for consent to collect patient data Technology issues

Intermittent or no internet access in remote locations

Multiple site EMR vendors

Stand-alone clinical management systems not linked to site EMR

Electronic patient summaries being scanned into EMRs or attached to a paper record

\section{Data analysis issues}

Missing data due to inconsistent data capture

Inconsistent interpretation of data dictionary definitions

Inconsistent programming for drop-down menus (multiple versus mutually exclusive response options)

Need to recode variables before merging data

Analysis of frequency variables (eg, exacerbations since last visit)

Analysis of complex variables (eg, asthma control with multiple parameters; yes/no versus raw values)

EMR Electronic medical record

nomenclatures endorsed by Infoway for data standards. Results were very positive with approximately $50 \%$ perfect match, $20 \%$ partial match and $30 \%$ no match for the elements in the ACM using SNOMED-CT ${ }^{\circledR}$, and full matches for spirometry elements using LOINC ${ }^{\circledR}(5)$.

As in any strategy, there was the need to have reliable and valid tools to evaluate care. Following the e-record pilot and in collaboration with Elizabeth Juniper, Professor Emeritus, McMaster University (Hamilton, Ontario), three paper versions of her Asthma Quality of Life Questionnaires (AQLQ) (6-8) were validated electronically: the Mini AQLQ (adult, 15-item) (9), the Mini Pediatric AQLQ (PAQLQ, 13-item)(10) and the Pediatric Asthma Caregiver Questionnaire (PACQLQ, 13-item) (11). Work is currently underway to establish a mechanism to have these tools readily accessible to primary care providers in Ontario that meets privacy and security standards. The vision is for such tools and data to be accessible to monitor, benchmark and evaluate care that will ultimately contribute to a provincial asthma registry.

In summary, standardized asthma management tools have been developed and implemented in the Government of Ontario-funded PCAP and in over 100 primary care locations in Ontario. There are standardized definitions for the majority of the care map elements and many of the data elements map to standardized medical nomenclature (SNOMED-CT ${ }^{\circledR}$ and LOINC ${ }^{\circledR}$ ). Three electronic AQLQs are available for use as a means to evaluate patient and program outcomes. A next step is to increase the uptake and use of the electronic version of the ACM in primary care in Ontario.

ACKNOWLEDGEMENT: This work was supported by the Government of Ontario.

\section{REFERENCES}

1. Boulet LP, Becker A, Bowie D, et al. Implementing practice guidelines: A workshop on guidelines dissemination and implementation with a focus on asthma and COPD. Can Respir J 2006;13(Suppl A):5-47.

2. To T, Cicutto L, Degani N, et al. Can a community evidence-based asthma care program improve clinical outcomes?: A longitudinal study. Med Care 2008;46:1257-66. 
3. Minard JP, Turcotte SE, Lougheed MD. Asthma electronic medical records in primary care: An integrative review. J Asthma 2010;47:895-912.

4. Minard JP, Olajos-Clow J, Garvey N, et al. Asthma electronic record for primary care: Development and pilot testing. Am J Respir Crit Care Med 2009;179:A4763.

5. Thomas N, Minard J, Lougheed MD. Primary care asthma programs asthma care map: Use of SNOMED-CT ${ }^{\circledR}$ and LOINC ${ }^{\circledR}$ to standardize terminology for electronic health records. Am J Respir Crit Care Med 2010;181:A4294.

6. Juniper EF, Guyatt GH, Cox FM, et al. Development and validation of the Mini Asthma Quality of Life Questionnaire. Eur Respir J 1999;14:32-8.

7. Juniper EF, Guyatt GH, Feeny DH, et al. Measuring quality of life in children with asthma. Qual Life Res 1996;5:35-46.

8. Juniper EF, Guyatt GH, Feeny DH, et al. Measuring quality of life in the parents of children with asthma. Qual Life Res 1996;5:27-34.

9. Olajos-Clow J, Minard J, Szpiro K, et al. Validation of an electronic version of the Mini Asthma Quality of Life Questionnaire. Respir Med 2010;104:658-67.

10.Minard J, Thomas N, Olajos-Clow J, et al. Validation of an electronic version of the Mini Pediatric Asthma Quality Of Life Questionnaire (Mini PAQLQ). Am J Respir Crit Care Med 2011;183:A1433.

11.Minard J, Thomas N, Olajos-Clow J, et al. Validation of an Electronic Version of The Pediatric Caregiver's Quality Of Life Questionnaire (PACQLQ). Am J Respir Crit Care Med 2011;183:A1432.

\section{SECTION IV. IS IT FEASIBLE TO USE INDICATORS TO COLLECT DATA ON ASTHMA PERFORMANCE IN THE PRIMARY CARE SETTING?}

Teresa To

\section{Rationale}

Asthma is the sixth most prevalent chronic disease overall and the most prevalent chronic disease in children, yet there is no standard way to document, describe or evaluate the delivery of asthma care in primary care settings. Previously, 15 evidence-based primary care asthma performance indicators (PC-APIs) were developed to evaluate the quality of asthma care in the primary care setting (1). We conducted two studies: the first was designed to test the feasibility of collecting data for each PC-API in the primary care setting and the second study was to test the feasibility of measuring these indicators using population-based health administrative data (HA-API).

\section{Methods}

In the PC-API study, primary care practitioners at three family health teams and two community health centres across Ontario participated in testing the feasibility of using an indicator form. For ease of data collection, the APIs were grouped into nine categories: use of pulmonary function tests, asthma medication use, asthma control, exacerbations, health care use, asthma action plan asthma education, smoking cessation and quality of life (Figure 1). Each site collected and submitted data on APIs using either a paper form returned by regular mail or fax, an Adobe ${ }^{\circledR}$ form printed and faxed or submitted by e-mail, or a web-based form. Physicians provided data on 10 consecutive prospective asthma patient visits and, using chart abstractions, 10 randomly selected retrospective patient visits. Data from the Ontario Asthma Surveillance Information System (OASIS) were used in the HA-API study. The OASIS used Ontario health administrative data to identify individuals with incident and prevalent asthma from 2003 to 2009. Six of the 15 APIs were available from the OASIS health administrative data.

The OASIS cohort was categorized into those cared by fee-forservice solo practitioners, fee-for-service Family Health Groups and salaried Primary Care Teams defined by the Government of Ontario. The HA-APIs were compared over time and across these primary care practice types.

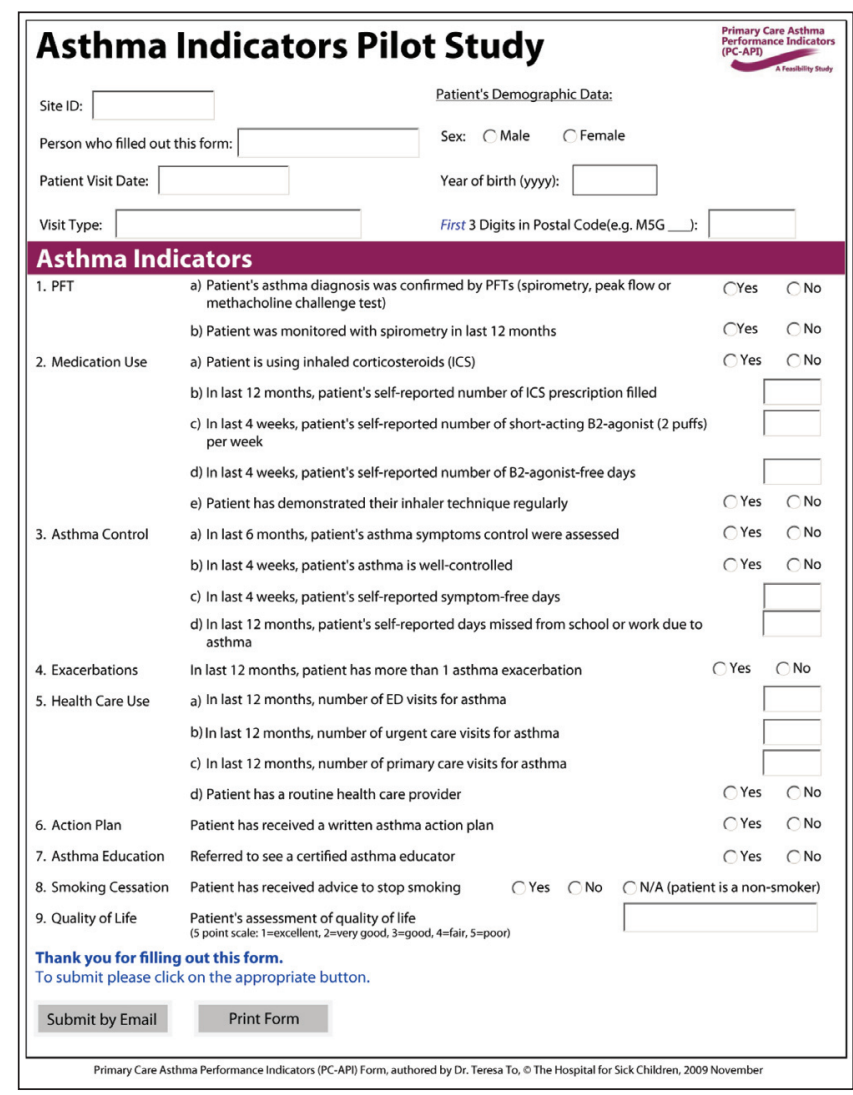

Figure 1) Primary Care Asthma Performance Indicators (PC-API). ED Emergency department; N/A Not applicable; PFT Pulmonary function testing

\section{Results}

In the PC-API study, asthma quality indicators were collected for 100 patients at the primary care setting. Health care providers found the API form easy to use. The feasibility study results suggested wide variations in asthma care across the participating sites in both prospective and retrospective patient visits (2). The HA-API study showed that there was an overall increase in the use of pulmonary function tests (PFTs) to diagnose and monitor asthma in Ontario from 2003 to 2009 (3). While there was an increase in the use of inhaled corticosteroids, the use of beta-agonists decreased slightly. Similar to the findings in the PC-API study, the HA-API study also showed variations in asthma care measured by the APIs among different physician practice types. For example, compared with others, solo practitioners had a lower rate of use of PFTs for asthma diagnosis and monitoring and their patients tended to have a lower rate of inhaled corticosteroid prescriptions filled.

\section{Conclusion}

Asthma performance indicators provide comparable and standardized information about the quality of asthma care among health care practitioners and across primary care settings. The use of these asthma performance indicators in both the community and at a population level is feasible and data collected could help improve asthma management and care. The population-based results can potentially be used as 'benchmarks' for the respective indicators. These benchmarks may enable practitioners to compare measured results with expected performance and help in establishing best asthma care practice.

ACKNOWLEDGEMENT: This work was supported by the Government of Ontario, Canadian Institutes of Health Research (PHE-85212) and the Public Health Agency of Canada. The opinions, results and conclusions reported are those of the author and are independent from the funding sources. 


\section{REFERENCES}

1. To T, Guttmann A, Lougheed MD, et al. Evidence-based performance indicators of primary care for asthma: A modified RAND Appropriateness Method. Int J Qual Health Care 2010;22:476-85.

2. To T, McLimont S, Daly C, Moores G, Gershon AS, Lougheed MD. Is it feasible to use indicators to collect data on asthma care performance in the primary care setting? A feasibility study. Prim Care Respir J 2011;20:452-3. (Epub 2011 Sep 21)

3. To T, Guan J, McLimont S, Gershon AS. Does the quality of asthma care vary between family practices? Am J Respir Crit Care Med 2011;183:A2922 (Abst).

\section{SECTION V. ENVIRONMENTAL SCAN: DATA STANDARDS FOR ASTHMA, COPD IN PRIMARY CARE IN CANADA AND ELSEWHERE}

\section{Mary-Ann Juurlink}

Building on previous work initiated as part of the PCAP EMR Project, the OLA and Queen's University Asthma Research Unit researchers conducted an environmental scan, funded by the Government of Ontario. The objective of the environmental scan was to identify any organizations/jurisdictions that have implemented an asthma/COPD data set including definitions and data standards in primary care.

Parties of interest, both national and international, were contacted to participate by providing their asthma/COPD data specifications. This resulted in a total of 20 data specifications mapped to the primary source, the OLA's ACM for Primary Care (1). The ACM is a paper tool designed to promote evidence-based asthma management during initial and follow-up assessments. The ACM currently is in use in more than 100 primary care locations in Ontario.

Feedback was received from the federal government, government agencies, provincial government ministries (British Columbia, Alberta, Manitoba, Ontario, Quebec, New Brunswick and Newfoundland \& Labrador), providers (both individual physicians and hospital representation) and the international community (United Kingdom, United States, Australia and the Netherlands).

The Department of National Defence and Correctional Service Canada were also contacted and reported they do not have any data sets for asthma care. The Canadian Institute for Health Information (CIHI) was not aware of any jurisdictional asthma initiatives beyond what Ontario is doing. However, CIHI's Primary Health Care EMR Content Standards project includes elements that are essential to asthma and COPD management. In the province of Quebec there is a major initiative from l'Institut national d'excellence en santé et en services sociaux (INESSS) developing quality indicators for some chronic care conditions; asthma and COPD are two of five conditions included in their mandate. Manitoba has not yet addressed asthma/COPD data sets and definitions but expressed interest in what Ontario is doing. New Brunswick reported they have several projects underway that would benefit from a consistent data set. There are many datasets being populated in Alberta but nothing yet finalized specifically for asthma/COPD measures or indicators that are standardized.

A preliminary gap-fit analysis was performed examining the various data sets including definitions and terminologies. The data sets were compared against three matching options:

- No match - The reference element was then appended to the source document (the OLA ACM).

- Partial/potential match - Similarity was noted.

- Match - The reference element was noted in the appropriate category. When the reference element was captured in a different section from the source, it was flagged.

This led to a consolidated data worksheet from which the initial draft information model for asthma/COPD was created. The draft information model is presented in Section VI 'Developing an Asthma/ COPD Data Standard - Data Disconnects'. The consolidated worksheet and draft information model will be the starting point for the next steps in the standards development life cycle for asthma/COPD.
There are still additional data that can be gathered after the environmental scan, namely from the Quebec INESSS project, the British Columbia Fraser Health Region COPD exacerbation clinical pathway and from other international initiatives in the United Kingdom, Australia and the Netherlands.

Discussion with the authors of these other specifications should be included in the stakeholder engagement process and their data specifications mapped to the draft consolidated worksheet and draft datainformation model. With sufficient requirements gathered to understand the issues, the next step is to work with the stakeholders to harmonize an initial draft standard.

The development of data standards is an ongoing iterative process supported by a maintenance process (eg, version release management). For example, additional lessons learned from ACM implementations in Ontario can be incorporated as part of the next steps. In the standards development and stakeholder engagement process, actual requirements are defined and refined.

Key observations include:

1) There are data elements and/or values that are not currently captured by the ACM for Primary Care (eg, comorbidities, education provided, self-management goal, height and weight, etc).

2) Some of the data elements in the source are captured in different sections in reference (eg, rhinitis is captured as allergy in source while it is captured as comorbidity in reference; sinusitis is captured as risk factor in source while it is captured as comorbidity in reference).

3) A number of the references do not differentiate between initial and follow-up visits (eg, Ontario EMR Specification v4; asthma diagnosis and management algorithm); as well, there is significant overlap in data captured for asthma and COPD, and there are data elements captured for COPD only (eg, tests, including blood work and sputum).

The results indicate that Ontario is leading the asthma/COPD data definition and standards development in Canada. Most provinces commented that they have not addressed data standards with respect to care maps but are very interested in what the PRESTINE project recommends.

\section{REFERENCE}

1. Garvey N, Lougheed D. Asthma in Ontario: Ontario's Asthma Plan of Action. Can Respir J 2006;13(Suppl A):5A-47A.

\section{SECTION VI. DEVELOPING AN ASTHMA/COPD DATA STANDARD - DATA DISCONNECTS Mary-Ann Juurlink}

A more in-depth analysis of the environmental scan was completed to further understand and discuss data disconnects. Data disconnects are a summary of the differences across the various data sets. This may include differences in data elements, definitions, labels, categories and formatting. Harmonization of these differences is necessary in developing data standards. A harmonization process eliminates unnecessary, redundant data, and aligns regional data in preparation for a pan-Canadian standard. This process enables improved consistency in the use of data elements, in their meaning and format. These data disconnects are outlined with examples, and potential PRESTINE project strategies are identified.

It is not easy to see the similarities and understand differences between data when viewing it in a spreadsheet. To align and harmonize data between specifications, the HL7 Health Development Framework was used. This describes a model-driven development approach that includes specifying an information model, data types, vocabularies and value sets. The draft asthma/COPD information model below represents all data categories and example data elements and values as seen in the environmental scan mapping exercise (Figure 2). 


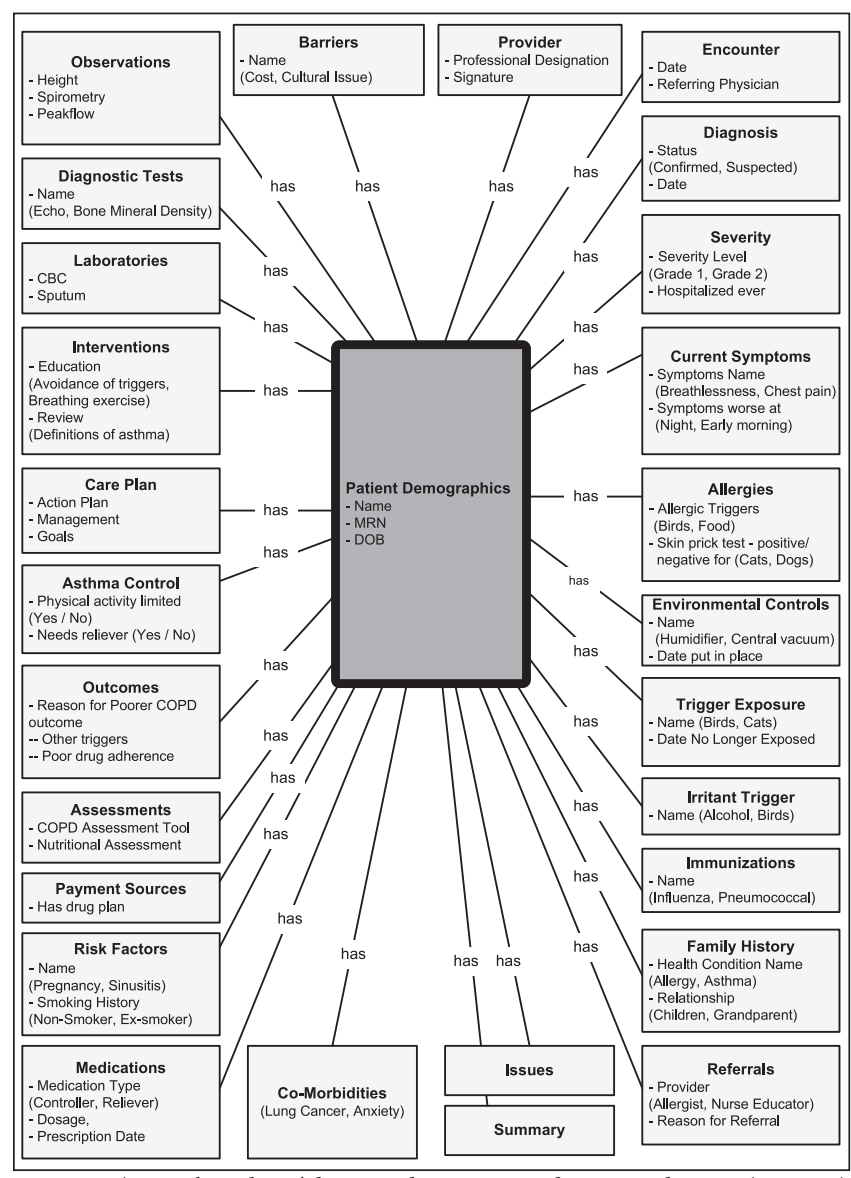

Figure 2) Draft asthma/chronic obstructive pulmonary disease (COPD) information model. CBC Complete blood count; DOB Date of birth; MRN Medical record number

Key data observations

There are a significant number of new data element sections or values identified in the references that are not currently captured by the OLA's ACM (eg, data elements for comorbidities, education provided, self-management goal, height and weight; and value sets for education regarding the chronic nature of disease).

In examining potentially new data elements or values sets, one must consider whether the data elements should be added, and if so, how the information should be classified or coded. Finally, it must be confirmed if the new data needs to be harmonized with other data. The harmonization/reconciliation activities would involve confirming requirements, and making changes to the information model. Furthermore, terminology maps for semantic interoperability across organizations would need to be created.

There are discrepancies in how similar elements are labelled, making it unclear as to what the element means and what is the intent of the data being captured. Examples are presented in Table 3.

To harmonize labelling of data, an understanding of how different stakeholders use similar data is required. This is achieved with stakeholders confirming the definition and the intent of information, eg, how is the data going to be used?

A number of the references do not differentiate between initial and follow-up visit information. This is apparent in the list of the asthma data elements approved by the OntarioMD 4.0 Specification, the organization responsible for certifying EMR vendors for primary care in Ontario. It is important to understand how the specification is intended to be used. Does an initial and follow-up visit differ, and if so, what are the differences? What are the data requirements for each?
TABLE 3

Similarities in labelling asthma/chronic obstructive pulmonary disease data elements across specifications

\begin{tabular}{ll}
\hline Source* $^{*}$ & References \\
\hline $\begin{array}{l}\text { Family history of allergy } \\
\text { or asthma }\end{array}$ & $\begin{array}{l}\text { Family history of asthma/atopic disorder } \\
\text { Other labels more vague, eg, family medical } \\
\text { history or concern }\end{array}$ \\
Irritant triggers & Environmental triggers \\
represented & Triggers \\
Tree/grass/weed pollen & Pollen/trees \\
& Grasses/ragweed \\
\hline
\end{tabular}

*Asthma Care Map for Primary Care

\section{TABLE 4}

Differences in data capture across specifications

\begin{tabular}{|c|c|c|}
\hline Element & Source category & Reference category \\
\hline $\begin{array}{l}\text { Hospitalized ever, prednisone } \\
\text { use ever }\end{array}$ & Severity & History of exacerbations \\
\hline Beta-blocker & Risk factor & Medication history \\
\hline Second hand smoke exposure & Risk factor & Smoking history \\
\hline Sinusitis & Risk factor & Comorbidity \\
\hline Rhinitis & Allergy history & Comorbidities \\
\hline
\end{tabular}

There is significant overlap in data captured for asthma and COPD; in addition, there are data elements captured for COPD only. Examples include:

- Tests for blood work and sputum are similar for asthma and COPD;

- COPD specifications saw the addition of a new category (comorbidities such as ischemic heart disease, the metabolic syndrome, etc); and

- A number of data elements/data values are categorized differently (eg, rhinitis captured as allergy [source], gastroesophageal reflux disease captured as risk factor [source], but both are captured in reasons for poorer COPD outcomes [reference], etc).

To understand the overlap and the need to harmonize the data elements, one needs to know what data is specific to COPD and asthma and how the differences will affect an information model.

Another observation is the variation in the level of detail being captured, lack of definitions and value sets. For example, the source document captures immunization (flu) yes/no; another reference captures influenza vaccination, date and past reaction. The source documents referrals and to whom (asthma education, specialist or other); another reference captures just referrals. To choose the most appropriate data element from the various specifications, the data element requires a clinical definition, ideally evidence-based, a value set and coded to an approved terminology. More work is needed to complete terminology and value sets for areas that are not yet standardized.

An additional observation is that elements are categorized differently. Table 4 provides examples of differences in the capture of data elements in the source document and other references.

When developing a standardized data set for any chronic condition, it is important to keep in mind a broader view of chronic disease and begin to understand what data elements are the same, different and where there is overlap. The creation of an e-Health information chronic disease model for Ontario, and ideally for Canada, would help prevent duplication of work and maximize the benefits of an EHR for all Canadians. Current efforts should be leveraged with other Canadian chronic disease initiatives such as the Western Health Information Collaborative and the Ontario Diabetes project. These initiatives will help inform PRESTINE and recommendations for respiratory standards for a pan-Canadian EHR. 


\section{SECTION VII. RESOURCES, RISKS/CHALLENGES AND GUIDING PRINCIPLES \\ Marc Koehn, Anne Van Dam, Janice Minard}

The PRESTINE national forum was convened to gather core planning parameters from stakeholders across the full spectrum of respiratory care, including clinicians, researchers, health informaticists and administrators. In addition to deliberations intended to establish core project management parameters such as the potential project scope, the overall approach and governance structure, the forum incorporated several breakout groups to brainstorm a number of additional topics intended to help provide guidance to the PRESTINE Steering Committee as outlined below:

- Resource inventory: An inventory of organizations, people and other assets that can be leveraged by the project;

- Risks/challenges: Areas of risk or challenges that the project needs to mitigate or address to meet its objectives; and

- Guiding principles: A set of principles to be considered by the PRESTINE Steering Committee as the project is further developed and, ultimately, delivered.

The following sections summarize the outcomes of discussions in these three topic areas.

\section{Resource inventory}

A key challenge for the PRESTINE steering committee will be to secure funding to resource the PRESTINE project and to ensure that it can meet its objectives within relatively tight timelines. As a collaborative effort among various stakeholder organizations, all willing to operate within the broader pan-Canadian standards milieu, an opportunity exists to leverage expertise, resources and funding from the members of this broad community. Key members of this community include Infoway's Standards Collaborative, CIHI and Statistics Canada, as well as the various jurisdictional players ranging from provincial or territorial e-Health programs through to the many implementers at the regional or Local Health Integration Network level across the country. These players offer access to a broad portfolio of e-Health standards to lay a foundation for respiratory-focused standards; a layered stakeholder engagement model and associated governance mechanisms to enable collaborative standards development and decision making; as well as a wide range of support services, including training and consulting to offer support to the PRESTINE project team. In addition, Infoway, as Canada's national e-Health funding catalyst, may be in a position to provide a degree of project funding support.

Stakeholders also noted the rich expertise available through collaborative engagement of the full spectrum of stakeholders including clinicians, informaticists, standards experts, administrators, researchers and vendors - whether engaged individually or through groups such as Information Technology Association of Canada Health. Perhaps the most significant resource identified, not only in the brainstorming breakouts but also through various broader discussion segments, was the CTS and its clinical guidelines - both in terms of the associated, well-established governance process as well as the guidelines themselves. The latter provide a sound clinical context while the governance process may provide a proven mechanism for stakeholder engagement and decision making.

\section{Risks/challenges}

A number of stakeholders looked well beyond the horizon at the many risks and challenges that need to be overcome in aggregating and analysing data pertaining to respiratory conditions such as asthma and COPD. Who coordinates data collection? How and where are data aggregated and stored? What are the privacy and data ownership implications?

Ultimately, it was recognized that PRESTINE, at this time, is intended to provide content and associated technical standards that help align data collection practices and that provide a foundation not only for exchanging and storing respiratory condition focused clinical data, but for making better, evidence-based decisions. Even within the narrower scope of a standards development project a series of risks and challenges surfaced, ranging from the complexities of effective panCanadian stakeholder engagement, through intellectual property considerations, bilingual support and potential difficulties in finding and building consensus around coding scales and systems, to the set of technical and human resource challenges in staffing and executing an effective standards project at a national level.

\section{Guiding principles}

Another key dimension of the forum's brainstorming activities included the identification of a set of guiding principles. This was intended to give those participants in the forum who might not be able to remain engaged throughout the duration of the PRESTINE project, to provide initial guidance for consideration by the project steering committee as the PRESTINE initiative is launched and brought into active operation.

Among the guiding principles that were identified by participants, the following stand out as the most significant:

- Build on what exists: The project must leverage existing standards and standards development processes and expand these in the area of respiratory care.

- Ensure that the common language being devised addresses the requirements of the full spectrum of stakeholders: The needs of a broad stakeholder community - including clinical, administrative and research interests - must be considered on a pan-Canadian, bilingual basis so that the common language can help address the needs of patients and patient communities, the ultimate stakeholder in the health care equation.

- Proceed in phases: Although the project should focus on a broad, long-term vision it should move towards this vision incrementally through feasible phases.

Through the establishment of these inventories and lists, the forum participants did their part in helping to shape and guide this important initiative.

\section{RECOMMENDATIONS AND CONCLUSION M Diane Lougheed, Louis-Philippe Boulet}

\section{Recommendations}

A key challenge for PRESTINE is the establishment of a concrete project scope to, among other things, assess resourcing requirements and establish a viable project schedule. As part of the preparation for the forum, the PRESTINE planning committee identified several potential scope dimensions that were explored by the participants and provided the following recommendations:

- Disease/condition focus: Whether there should be an initial focus and, if so, what should constitute this focus? For example, are asthma and COPD reasonable starting points?

Recommendation: The group agreed that asthma and COPD would be reasonable initial focus areas, but cautioned against a disease-focused design approach because data capture before diagnosis is highly relevant. Moreover, they observed that broader issues, such as smoking behaviour and cessation, are prime candidates for this community to address and provide leadership direction, subject to other projects that are underway.

- Targeted clinical setting(s): Whether the specification should be focused on one or more particular clinical settings (eg, acute care, primary health, etc) and, if so, what setting or settings are included?

Recommendation: There was general consensus that primary care is a reasonable initial focus setting of care. However, it should not be addressed in isolation given the movement of patients across the continuum of care and the need for an incentive for primary care providers to be engaged in this process. Furthermore, if primary care is a focal area, stakeholder engagement should be broad and include other clinical groups (eg, pharmacists). 
- Community of stakeholders: What is the community of stakeholders to be included in governance and/or operational groups?

Recommendation: The full spectrum of stakeholders clearly needs to be considered including clinicians (of various professional groups), regulatory agencies (both government and colleges), researchers/academics, patients, vendors and health administrators. This will require the development of a full stakeholder assessment matrix to ensure not only appropriate coverage but to plan the level of engagement. Scope cannot clearly be delineated until such an analysis occurs.

- Standardization end goal: Is an end goal of the process to see the specifications designated a "pan-Canadian standard" by the Infoway Standards Collaborative? What type of standard is sought ... content standards for a minimum data set, data transmission specifications?

Recommendation: There appeared to be strong consensus that formal approval be sought at both a national level and also through jurisdictional processes (eg, provincial health standards associations or committees). It was also observed that the respiratory standards portfolio will eventually need to address not only a data set (whether minimum or otherwise), but potentially also data transmission specifications. It was noted that standardized terminology is a key facet of any clinical specification.

\section{CONCLUSION}

The PRESTINE National Forum succeeded in obtaining input from relevant stakeholders. Forum participants concurred that there is a need to develop respiratory-related data definitions and standards for inclusion in EHR. Participants endorsed the establishment of a Steering Committee and working groups. The Steering Committee will build on the recommendations of the national forum; receive and approve recommendations from the working groups; confirm data standards and definitions for entry into the EHR; identify test pilot venues; develop a process for integrating respiratory data elements and standards with existing chronic disease models; develop a communications and outreach plan; confirm project budget, project work plan and project change management plan; identify sustainable resources for the ongoing development of the standards; and establish criteria and process for evaluating outcomes.

This represents an opportunity for the CRGC, CTS Clinical Assemblies, health care providers, administrators, and health informatics experts to collaborate and to promote guidelines implementation by integrating key recommendations into current care via the EHR.

ACKNOWLEDGEMENTS: The authors are grateful to the members of the PRESTINE Planning Committee: Janice Minard, Anne Van Dam,
Nancy Garvey, Ana McPherson, Shari Dworkin, Andrea MacLean, Connie Côté, the co-Chairs Diane Lougheed and Louis-Philippe Boulet, and the facilitator Marc Koehn for their help with the organization of the national forum, and Julie Carrier for recording the meeting notes. The forum was made possible with contributions from the following partners: the Canadian Thoracic Society, the Ontario Lung Association and the National Lung Health Framework.

The authors also thank the National Forum participants:

Louis-Philippe Boulet, Institut universitaire de cardiologie et de pneumologie de Québec, Québec, Québec; Patricia Camp, University of British Columbia, Vancouver, British Columbia; Julie Carrier, National Lung Health Framework, Ottawa; Lisa Colizza, McMaster University, Hamilton; Connie Côté, National Lung Health Framework, Ottawa, Ontario; Francine Ducharme, Centre de Recherche du CHU Sainte-Justine, Montréal, Québec; Shari Dworkin, Canada Health Infoway, Toronto; Madonna Ferrone, Respiratory Therapist/Educator, Windsor; Nancy Garvey, Government of Ontario, Toronto; Andrea Gershon, Sunnybrook Health Sciences Centre, Toronto, Ontario; Brian Graham, Saskatchewan Lung Association, Saskatoon, Saskatchewan; Samir Gupta, University of Toronto/St Michael's Hospital, Toronto, Ontario; Mary Ann Juurlink, MAJ Associates, Chelsea, Québec, Québec; Pamela Kaduri, Centre for Addiction and Mental Health, Toronto; Alan Kaplan, Canadian Royal College of Family Physicians, Richmond Hill, Ontario; Marc Koehn, Gordon Point Informatics Ltd, Victoria, British Columbia; Chris Licskai, University of Western Ontario, London; Diane Lougheed, Kingston General Hospital, Queen's University, Kingston; Andrea MacLean, Canada Health Infoway, Toronto; Ana MacPherson, Ontario Lung Association, Toronto; Louise McRae, Public Health Agency of Canada, Ottawa; Janice Minard, Kingston General Hospital, Queen's University, Kingston; Todd Sands, Centre for Smart Community Innovation University of Windsor, Windsor; Sue Schneider, eHealth Ontario, Toronto; Peter Selby, Centre for Addiction and Mental Health, Toronto, Ontario; Kathleen Spurr, Dalhousie University, Halifax, Nova Scotia; Andrea Stevens-Lavigne, Ontario Lung Association, Toronto; Janet Sutherland, Canadian Thoracic Society/Canadian Respiratory Health Professionals, Ottawa; Itamar Tamari, Stonegate Community Health Centre, Etobicoke, Ontario; Hamid Tavakoli, University of British Columbia, Vancouver, British Columbia; Walley Temple, University of Calgary, Calgary, Alberta; Teresa To, SickKids Hospital, Toronto; and Anne Van Dam, Canadian Lung Association, Ottawa, Ontario 


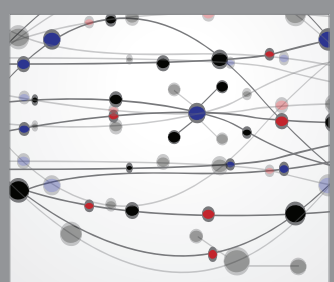

The Scientific World Journal
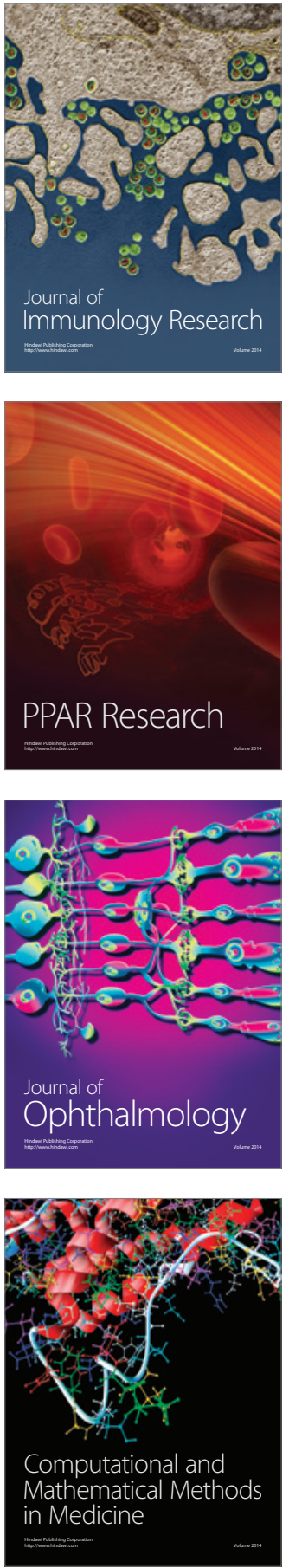

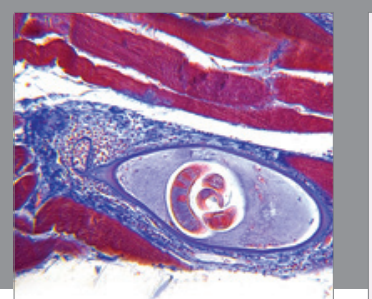

Gastroenterology Research and Practice

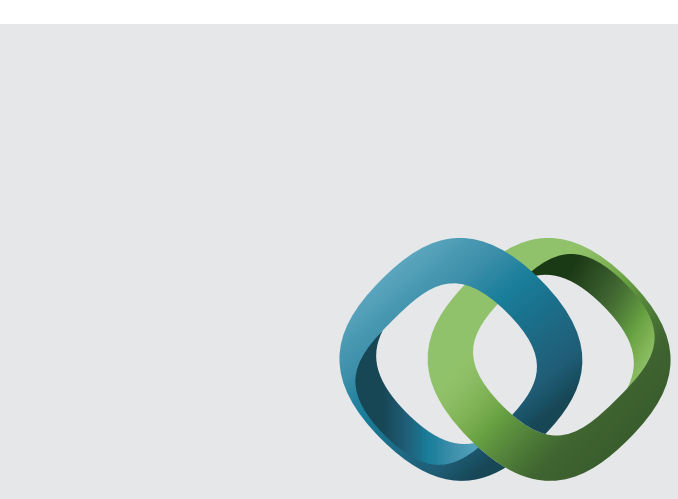

\section{Hindawi}

Submit your manuscripts at

http://www.hindawi.com
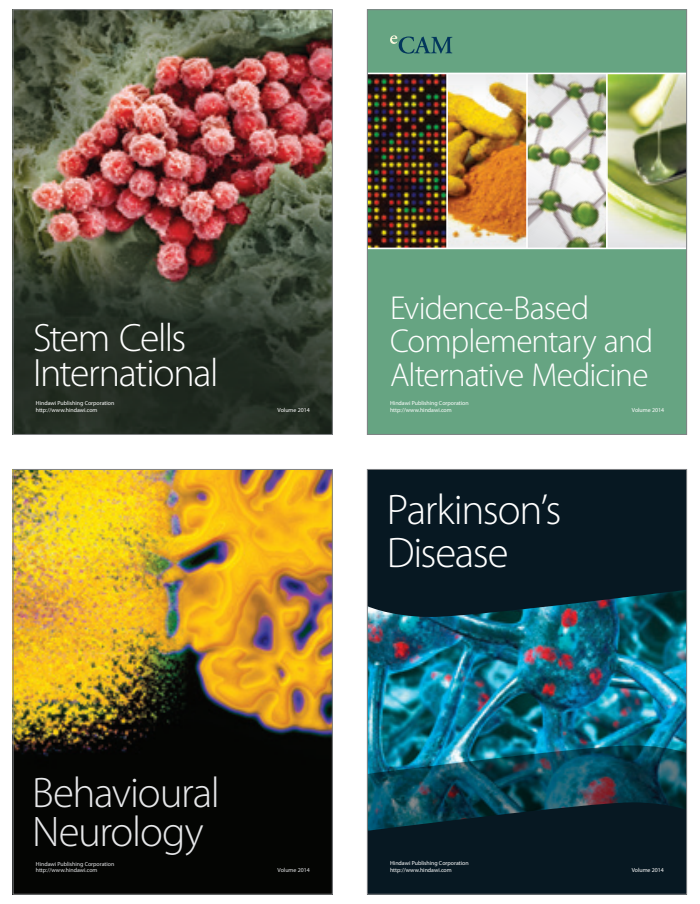
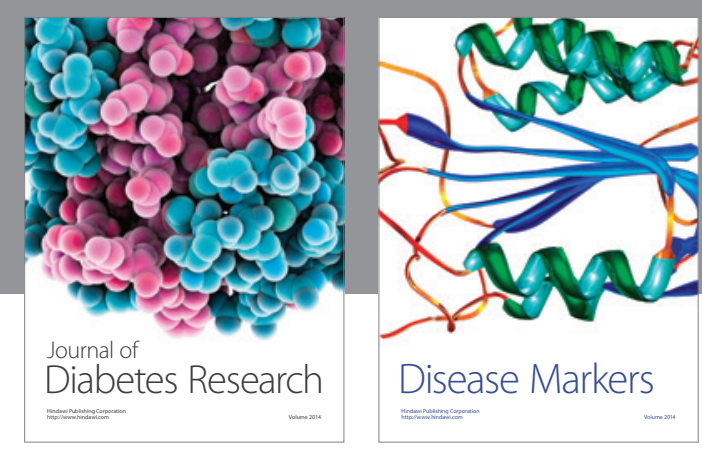

Disease Markers
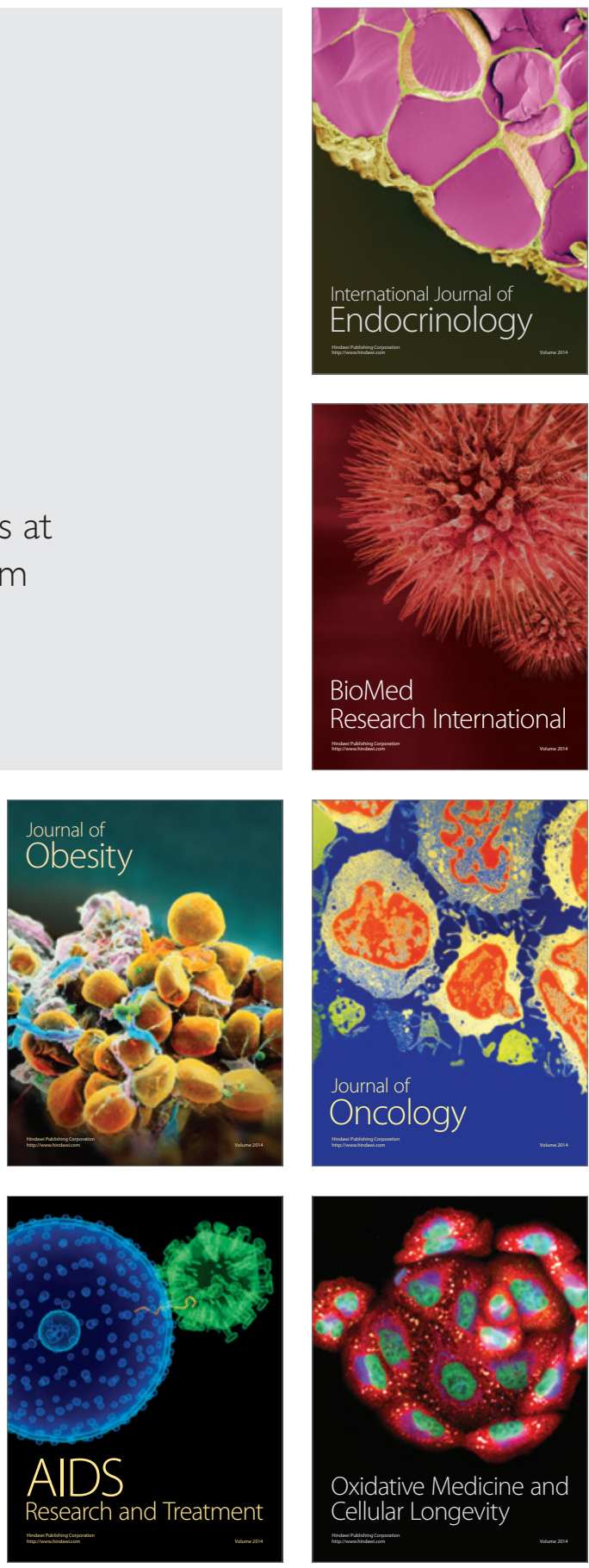